Buletin Ilmiah Mat, Stat, dan Terapannya (Bimaster)

Volume 08, No. 2 (2019), hal 371-378.

\title{
PENDEKATAN BAYESIAN SELF PADA MODEL SURVIVAL EKSPONENSIAL- GAMMA UNTUK MENENTUKAN PREMI TUNGGAL BERSIH DWIGUNA $k$-TAHUN
}

\author{
Lisa Noviani, Setyo Wira Rizki, Naomi Nessyana Debataraja
}

\begin{abstract}
INTISARI
Analisis survival adalah sekumpulan aturan atau prosedur dalam ilmu statistika untuk menganalisis data dengan memperhatikan variabel waktu dimulai dari berlangsungnya suatu kejadian sampai akhir kejadian. Dalam penelitian ini analisis survival digunakan untuk menganalisis fungsi survival eksponensial dengan parameter yang telah diestimasi menggunakan Pendekatan Bayesian SELF dengan prior gamma. Selanjutnya, model survival yang telah diestimasi digunakan dalam model Actuarial Present Value (APV) asuransi dwiguna. Pada penelitian ini digunakan premi tunggal bersih yaitu jenis premi asuransi yang tidak memperhatikan faktor biaya (anuitas). Tujuan Penelitian ini adalah menentukan premi tunggal bersih dwiguna $k$-tahun untuk seseorang yang berusia dari 1 sampai 55 tahun dengan jumlah sampel sebanyak 55 orang, dalam jangka 10 tahun, 15 tahun dan 20 tahun. Berdasarkan hasil perhitungan didapatkan bahwa harga premi untuk seseorang yang berusia 1 sampai 55 tahun, berjangka 10 tahun sebesar Rp61.551.502,7,- berjangka 15 tahun adalah Rp51.490.493,06,- dan berjangka 20 tahun adalah Rp45.394.374,22,-. Sehingga disimpulkan semakin lama jangka pembayaran semakin murah harga premi yang dibayarkan.
\end{abstract}

Kata Kunci : Prior, Actuarial Present Value, estimasi model.

\section{PENDAHULUAN}

Asuransi dwiguna $k$-tahun merupakan salah satu jenis asuransi jiwa yang khusus menangani risiko akibat kematian yaitu yang menawarkan dua manfaat sekaligus, yaitu manfaat dari asuransi dwiguna berjangka $k$-tahun dan dwiguna murni. Pembayaran premi pada asuransi dapat dilakukan secara sekaligus saat kontrak terjadi selanjutnya tidak ada pembayaran lagi disebut dengan premi tunggal bersih [1]. Dalam menghitung premi tunggal bersih dibutuhkan nilai Actuarial Present Value (APV) berdasarkan jenis asuransi yang diambil. Pada model APV terdapat fungsi survival seorang peserta asuransi yang mengikuti polis. Fungsi survival dianalisis dengan menggunakan analisis uji tahan hidup (analisis survival). Permodelan analisis survival ada dua yaitu model parametrik dan nonparametrik. Beberapa model parametrik yaitu dengan data yang berdistribusi eksponensial, distribusi weibull, distribusi log-logistik, dan distribusi gamma. Setelah diketahui distribusi data langkah selanjutnya mengestimasi parameter. Dalam mengestimasi parameter dapat digunakan dua pendekatan yaitu pendekatan klasik (classical approach) dan Pendekatan Bayesian (Bayesian Approach) atau dikenal dengan metode Bayesian [2]. Beberapa pendekatan dari metode estimasi Bayesian yang dapat digunakan untuk mengestimasi parameter distribusi yaitu Generalised Noninformative Prior, Linear Exponential Loss Function, Lindley Approximation, General Entropy Loss Function (GELF), dan Squared Error Loss Function (SELF) [2]. Tujuan penelitian ini yaitu menerapkan model premi dwiguna $k$-tahun dengan estimasi model survival eksponensial Bayesian SELF dalam perhitungan harga premi tunggal bersih dwiguna berjangka 10 tahun, 15 tahun dan 20 tahun. Batasan masalah pada penelitian ini adalah (1) Distribusi data adalah distribusi eksponensial. (2) Distribusi prior yang digunakan untuk estimasi Bayesian adalah distribusi gamma. (3) Jenis asuransi yang digunakan adalah asuransi jiwa dwiguna $k$-tahun diskrit. (4) Menggunakan jenis premi tunggal bersih. Adapun pada metodotologi penelitian ini dimulai terlebih dahulu dilakukan uji kecocokan model (Goodness of Fit Test) dengan uji Kolmogorov-Smirnov untuk mengetahui data berdistribusi eksponensial $f(t ; \theta)$ atau tidak. Setelah itu menentukan model survival dari fungsi distribusi kumulatif $F(t)$, fungsi survival $S(t)$ dari distribusi eksponensial. Tahap selanjutnya mengestimasi parameter $\theta$ untuk model survival 
Bayesian SELF $\hat{S}(t)_{B S}$, dimulai dengan penentuan fungsi likelihood pada data usia $L\left(t_{j} ; \theta\right)$. Fungsi likelihood sebagai distribusi sampel pada metode Bayes. Langkah berikutnya yaitu menentukan distribusi prior $f(\theta)$ dari distribusi eksponensial. Setelah memperoleh fungsi likelihood pada data usia $L\left(t_{j} ; \theta,\right)$ dan distribusi prior $f(\theta)$, selanjutnya menentukan peluang marjinal $f\left(t_{j}\right)$ yang akan menjadi bagian dalam perumusan posterior $f\left(\theta \mid t_{j}\right)$ (metode Bayes) yang akan menghasilkan nilai parameter $\hat{\theta}$. Setelah itu, mendapatkan model survival Bayesian SELF $\hat{S}(t)_{B S}$ yang akan diterapkan ke model APV asuransi dwiguna $k$-tahun yang merupakan penjumlahan dari asuransi berjangka $k$-tahun dan dwiguna murni. Langkah selanjutnya menghitung nilai premi tunggal 10 tahun, 15 tahun dan 20 tahun.

\section{DISTRIBUSI EKSPONENSIAL}

Jika $T$ adalah waktu survival yang mengikuti distribusi eksponensial dengan parameter $\theta$, fungsi kepadatan peluang distribusi eksponensial ialah [3]:

$$
f(t ; \theta)=\theta e^{-\theta t}, t \geq 0, \theta>0
$$

Fungsi distribusi kumulatif untuk distribusi eksponensial ialah [3]:

$$
F(t ; \theta)=1-e^{-\theta t}, t \geq 0, \theta>0
$$

Fungsi survival dari distribusi eksponensial sebagai berikut [3]:

$$
S(t ; \theta)=e^{-\theta t}, t \geq 0
$$

\section{METODE BAYESIAN}

Metode Bayesian merupakan salah satu inferensi dalam ilmu statistik yang memandang parameter $\theta$ sebagai variabel random pada distribusi prior (sebelum) atau distribusi yang memberikan informasi awal. Distribusi prior tersebut diharapkan dapat berkonjugasi dengan distribusi data dengan suatu parameter tertentu. Penggabungan distribusi prior (sebelum) dengan fungsi likelihood (distribusi sampel) yang membentuk peluang bersyarat dan menghasilkan distribusi posterior [4]. Fungsi likelihood pada data usia dinyatakan sebagai berikut [5]:

$$
\begin{gathered}
L\left(t_{j} ; \theta\right)=f\left(t_{1} ; \theta\right) f\left(t_{2} ; \theta\right) \cdots f\left(t_{n} ; \theta\right) \\
=\prod_{j=1}^{n} f\left(t_{j} ; \theta\right)
\end{gathered}
$$

dimana $L\left(t_{j} ; \theta\right)$ menyatakan fungsi likelihood, $\theta$ parameter yang akan diestimasi, $t$ menyatakan usia seseorang dimulai dari usia satu tahun $\left(t_{1}\right)$ sampai usia seseorang yang berusia $n$ tahun $\left(t_{n}\right)$ dan $\prod_{j=1}^{n} f\left(t_{j} ; \theta\right)$ yang menyatakan sigma perkalian dari $f\left(t_{1} ; \theta\right) . f\left(t_{2} ; \theta\right) . f\left(t_{3} ; \theta\right) \ldots . . f\left(t_{n} ; \theta\right)$, sehingga estimasi fungsi likelihood dari distribusi eksponensial sebagai berikut:

$$
\begin{aligned}
L\left(t_{j} ; \theta\right) & =\prod_{j=1}^{n} f\left(t_{j} ; \theta\right) \\
& =\theta^{n} e^{-\left(\theta \sum_{i=1}^{n} t_{i}\right)}
\end{aligned}
$$

Dalam kasus ini, distribusi gamma ditetapkan sebagai distribusi prior sekawan untuk distribusi eksponensial, sehingga distribusi prior untuk $\theta$ ialah:

$$
f(\theta)=\frac{\beta^{\alpha}}{\Gamma(\alpha)} \theta^{\alpha-1} e^{-\beta \theta} \quad \alpha>0, \beta>0, \theta>0
$$

dengan $\alpha=1$ dan $\beta=E(T)$ [2]. 
setelah menentukan distribusi likelihood dan distribusi prior maka selanjutnya penentuan distribusi posterior, yang dituliskan sebagai berikut [4]:

$$
f\left(\theta \mid t_{j}\right)=\frac{f(\theta) L\left(t_{j} ; \theta\right)}{\int_{0}^{\infty} f(\theta) L\left(t_{j} ; \theta\right) d \theta}
$$

dengan $f\left(\theta \mid t_{j}\right)$ merupakan distribusi posterior dan $f(\theta)$ merupakan distribusi prior, sedangkan $L\left(t_{j} ; \theta\right)$ merupakan fungsi likelihood.

Jika $T \sim \operatorname{Eksponensial}(\theta)$ dan fungsi kepadatan peluang distribusi prior $\theta \sim \operatorname{Gamma}(\alpha, \beta)$, maka distribusi posterior dapat dinyatakan sebagai fungsi peluang bersyarat dari $\theta$ dengan $t$ diketahui, sehingga distribusi posterior juga dapat dinyatakan sebagai berikut [2]:

$$
f\left(\theta \mid t_{j}\right)=\frac{f\left(\theta ; t_{j}\right)}{f\left(t_{j}\right)}
$$

Karena $f\left(\theta, t_{j}\right)$ dapat dinyatakan sebagai $f(\theta) L\left(t_{j} ; \theta\right)$, dimana $L\left(t_{j} ; \theta\right)$ merupakan fungsi likelihood dan $f(\theta)$ merupakan distribusi prior. Berdasarkan Persamaan (1) dan (2) maka,

$$
\begin{aligned}
& f\left(\theta ; t_{j}\right)=f(\theta) L\left(t_{j} ; \theta\right) \\
& f\left(\theta ; t_{j}\right)=\frac{\beta^{\alpha}}{\Gamma(\alpha)} \theta^{\alpha+n-1} e^{-\theta\left(\beta+\sum_{j=1}^{n} t_{j}\right)}
\end{aligned}
$$

Selanjutnya peluang marjinal dinyatakan sebagai berikut:

$$
\begin{aligned}
& f\left(t_{j}\right)=\int_{0}^{\infty} f(\theta) L\left(t_{j} ; \theta\right) d \theta \\
& f\left(t_{j}\right)=\frac{\beta^{\alpha}}{\Gamma(\alpha)} \Gamma(\alpha+n)\left(\frac{1}{\beta+\sum_{j=1}^{n} t_{j}}\right)^{\alpha+n}
\end{aligned}
$$

maka berdasarkan Persamaan (3) dan (4) diperoleh distribusi posterior sebagai berikut:

$$
f\left(\theta \mid t_{j}\right)=\frac{\left.\theta^{\alpha+n-1} e^{-\theta\left(\beta+\sum_{j=1}^{n} t_{j}\right.}\right)}{\Gamma(\alpha+n)\left(\frac{1}{\beta+\sum_{j=1}^{n} t_{j}}\right)^{\alpha+n}=\frac{\left.\theta^{\alpha+n-1} e^{-\theta\left(\beta+\sum_{j=1}^{n} t_{j}\right.}\right)\left(\beta+\sum_{j=1}^{n} t_{j}\right)^{\alpha+n}}{\Gamma(\alpha+n)}}
$$

Berdasarkan Persamaan (5), diketahui bahwa posterior berdistribusi gamma $\left(\alpha+n, \sum_{j=1}^{n} t_{j}+\beta\right)$

METODE BAYESIAN SELF

Estimasi parameter yang digunakan dalam kasus ini menggunakan Symmetric Loss Function yang dikenal sebagai SELF atau Squared Error Loss Function, dimana loss function untuk SELF didefinisikan sebagai berikut [6]:

$$
L(\theta, \widehat{\theta})=(\widehat{\theta}-\theta)^{2} \quad 0<\theta<\infty
$$


dengan $\hat{\theta}$ merupakan estimator Bayesian untuk $\theta$ dengan pendekatan SELF. Estimasi Bayesian SELF dari $\theta$ pada distribusi eksponensial yaitu diperoleh dengan meminimumkan ekspektasi loss function maka diperoleh sebagai berikut [2]:

$$
\widehat{\theta}=E(\theta)
$$

dengan mensubtitusi Persamaan (5) diperoleh hasil estimasi parameter menggunakan metode Bayesian SELF ialah:

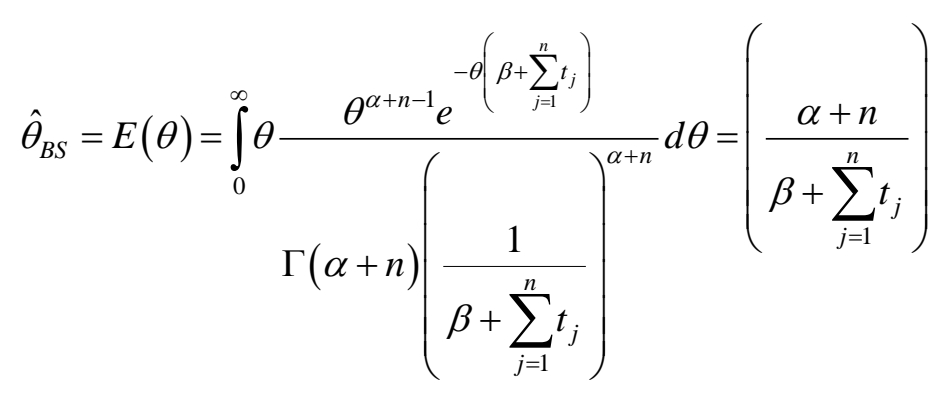

Berdasarkan Persamaan (6), maka estimasi parameter metode Bayesian SELF dari distribusi eksponensial pada data usia untuk fungsi survival diperoleh:

$$
\hat{S}(t)_{B S}=\left(t_{j} ; \hat{\theta}\right)=e^{\hat{\theta}_{B S} t_{j}}=e^{-\left(\frac{\alpha+n}{\beta+\sum_{j=1}^{n} t_{j}}\right) t_{j}}
$$

dengan fungsi survival untuk $t+k$ dapat dituliskan,

$$
\hat{S}(t+k)_{B S}=e^{-\left(\frac{\alpha+n}{\beta+\sum_{j=1}^{n} t_{j}}\right)} t_{j}+k
$$

dan fungsi survival untuk $t+k+1$, dituliskan:

$$
S(t+k+1)_{B S}=e^{-\left(\frac{\alpha+n}{\beta+\sum_{j=1}^{n} t_{j}}\right) t_{j}+k+1}
$$

\section{FUNGSI PELUANG HIDUP DAN PELUANG MENINGGAL}

Pemodelan APV dalam aktuaria menggunakan fungsi peluang hidup, yaitu seseorang berpeluang hidup dan meninggal. Peluang hidup seseorang didapatkan dengan mengestimasi fungsi survival yang dinotasikan dengan ${ }_{k} p_{t}$ yaitu menyatakan peluang seseorang yang berusia $t$ tahun dapat bertahan hidup hingga $t+k$ tahun [7]. Berdasarkan mensubtitusikan Persamaan (7) dan (8) diperoleh estimasi fungsi peluang hidup menggunakan fungsi survival Bayesian SELF sebagai berikut:

$$
\left({ }_{k} p_{t}\right)_{B S}=\frac{\hat{S}(t+k)_{B S}}{\hat{S}(t)_{B S}}=\frac{e^{-\left[\frac{\alpha+n}{\beta+\sum_{j=1}^{n} t_{j}} t_{j}+k\right.}}{e^{\left[\frac{\alpha+n}{\beta+\sum_{j=1}^{n} t_{j}} t_{j}\right.}}=e^{-\left[\frac{\alpha+n}{\beta+\sum_{j=1}^{n} t_{j}}\right] k}
$$


sedangkan peluang seseorang meninggal dinotasikan dengan $q_{t+k}$. Sehingga estimasi peluang seseorang meninggal menggunakan fungsi survival Bayesian SELF, berdasarkan Persamaan (8) dan (9), dinyatakan dengan:

$$
\begin{gathered}
\left(q_{t+k}\right)_{B S}=1-\left(p_{t+k}\right)_{B S}=1-\frac{\hat{S}(t+k+1)_{B S}}{\hat{S}(t+k)_{B S}} \\
=1-\frac{e^{-\left(\frac{\alpha+n}{\beta+\sum_{j=1}^{n} t_{j}} t_{j}+k+1\right.}}{e^{\left(\frac{\alpha+n}{\beta+\sum_{j=1}^{n} t_{j}}\right) t_{j}+k}}=1-e^{-\left(\frac{\alpha+n}{\beta+\sum_{j=1}^{n} t_{j}}\right)}
\end{gathered}
$$

\section{FAKTOR DISKON}

Pemodelan APV asuransi berjangka $k$-tahun terdapat faktor diskon $v$ merupakan faktor yang dipengaruhi oleh suku bunga, dalam penelitian ini digunakan suku bunga sederhana sehingga faktor diskon dinyatakan sebagai berikut [1]:

$$
v=\frac{1}{(1+i)}
$$

di mana: $\quad v=$ Faktor diskon

$i=$ Suku bunga

\section{UJI KECOCOKAN (GOODNESS OF FIT TEST)}

Uji kecocokan (Goodness Of Fit Test) adalah pengujian kecocokan antara distribusi sampel dengan distribusi tertentu, hipotesis pada uji Kolmogorov-Smirnov adalah sebagai berikut [8]:

$H_{0}$ : Data mengikuti distribusi yang eksponensial

$H_{l}$ : Data tidak mengikuti distribusi yang eksponensial

Pengambilan keputusan akhir untuk menerima atau menolak $H_{0}$ berdasarkan daerah kritis $\alpha$ dengan $p$-value. Jika diambil nilai $\alpha=5 \%$ maka kondisi $H_{0}$ diterima jika nilai $p$-value $>\alpha=5 \%$ dan sebaliknya $H_{0}$ ditolak jika nilai $p$-value $\leq \alpha=5 \%$.

\section{MODEL APV PREMI TUNGGAL BERSIH DWIGUNA $\boldsymbol{k}$-TAHUN}

Asuransi dwiguna (endowment) $k$-tahun dengan jumlah unit pembayaran pada akhir tahun kematian adalah kombinasi dari asuransi berjangka $k$-tahun dan asuransi dwiguna murni (pure endowment) $k$ tahun [7]. Maka APV premi asuransi dwiguna dinyatakan sebagai berikut:

$$
P\left(A_{t: \bar{k}}\right)=B\left(\left(\sum_{k=0}^{n-1} v_{k}^{k+1} p_{t} q_{t+k}\right)+\left(v_{k}^{k} p_{t}\right)\right)
$$

dengan:

$B \quad=$ Manfaat yang diterima

$v \quad=$ Faktor diskon

${ }_{k} p_{t} \quad=$ Peluang seseorang yang hidup pada usia $\mathrm{t}$ tahun sampai $\mathrm{t}+\mathrm{k}$ tahun

$q_{t+k} \quad=$ Peluang seseorang pada usia $\mathrm{t}$ tahun akan meninggal pada usia $\mathrm{k}$ tahun

$P\left(A_{t: \bar{k}}\right)=$ Premi asuransi dwiguna $k$-tahun 
Model APV pada asuransi berjangka $k$-tahun yaitu [1]:

$$
A_{1: k}=\sum_{k=0}^{n-1} v^{k+1}{ }_{k} p_{t} q_{t+k}
$$

Berdasarkan Persamaan (14) untuk mendapatkan model APV asuransi berjangka $k$-tahun dengan estimasi model survival eksponensial Bayesian SELF, berdasarkan Persamaan (10), (11), dan (12) yang diperoleh hasil sebagai berikut:

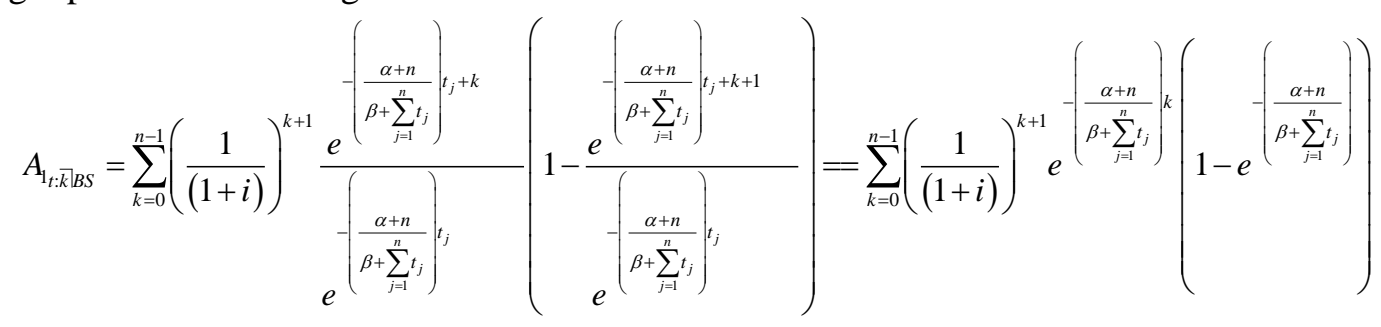

dengan mensubtitusikan Persamaan (10) dan (12) diperoleh model APV asuransi dwiguna murni dengan model survival eksponensial Beyesian SELF yang dituliskan sebagai berikut [1]:

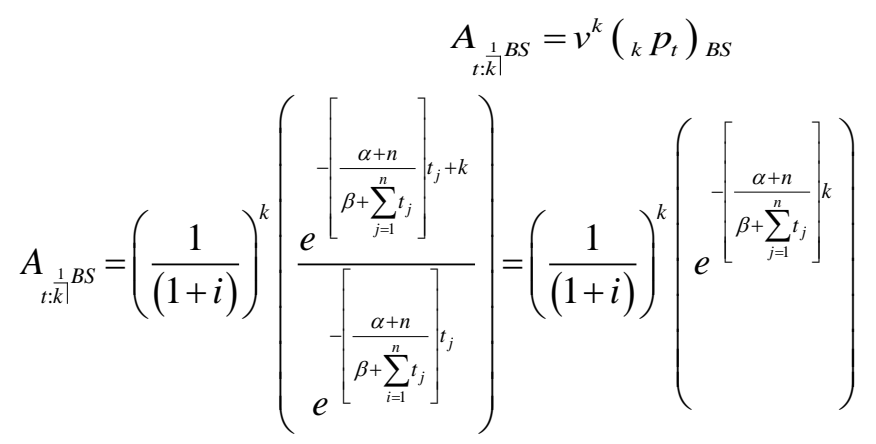

Berdasarkan rumus premi tunggal dwiguna $k$-tahun pada Persamaan (13), yaitu penjumlahan antara APV asuransi berjangka $k$ - tahun Persamaan (15) dan APV asuransi dwiguna murni pada Persamaan (16). Sehingga diperoleh model premi dwiguna $k$-tahun menggunakan model survival eksponensial dengan pendekatan Bayesian SELF sebagai berikut:

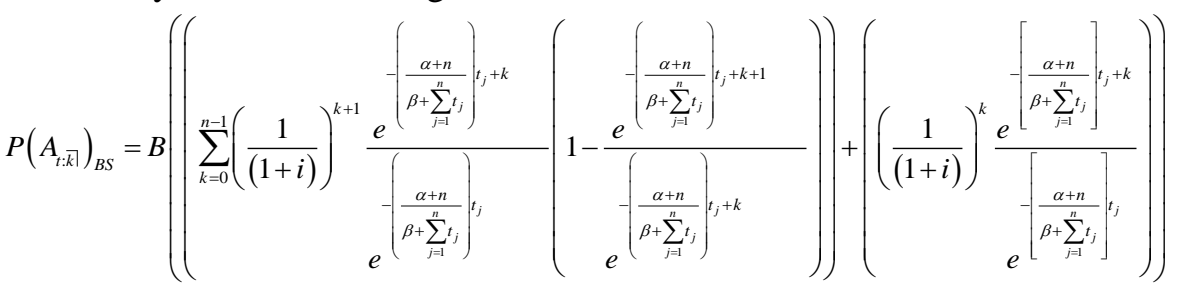

$$
\begin{aligned}
& =B\left(\left(\sum_{k=0}^{n-1}\left(\frac{1}{(1+i)}\right)^{k+1} e^{-\left(\frac{\alpha+n}{\beta+\sum_{j=1}^{n} t_{j}}\right)}\left(1-e^{-\left(\frac{\alpha+n}{\beta+\sum_{j=1}^{n} t_{j}}\right)}\right)\right)+\left(\left(\frac{1}{(1+i)}\right)^{k-\left(\frac{\alpha+n}{\beta+\sum_{j=1}^{n} t_{j}}\right)}\right)\right)
\end{aligned}
$$

\section{PENERAPAN MODEL SURVIVAL EKSPONENSIAL BAYESIAN SELF PADA PERHITUNGAN PREMI DWIGUNA $k$-TAHUN}

Studi kasus pada penelitian ini menggunakan data usia orang di mulai dari usia 1 sampai 55. Dengan jangka waktu pembayaran selama 10 tahun, 15 tahun dan 20 tahun. hasil uji distribusi data usia menggunakan uji Kolmogorov Smirnov pada aplikasi SPSS, diperolehan $p$-value $=0,099>$ nilai $\alpha$ $=0,05$. Berdasarkan hal tersebut maka disimpulkan bahwa hipotesis $H_{0}$ diterima atau data berdistribusi eksponensial. Setelah menguji distribusi data selanjutnya dapat memulai proses menentukan harga premi dwiguna $k$-tahun dengan model survival eksponensial dengan Pendekatan Bayesian SELF. 
Dalam perhitungan harga premi, ada beberapa unsur-unsur pembentuk model premi yang sudah diketahui melalui data, penentuan institusi atau penentuan dari peneliti, yaitu: $n=55 ; \sum_{j=1}^{n} t_{j}=1540$; $\alpha=1 ; \beta=\mathrm{E}(\mathrm{T})=28$ [2]; dan $i=0,06$ [9]. Berdasarkan Persamaan (14) didapatkan harga premi untuk seseorang yang berusia 28 tahun dengan jangka pembayaran 10 tahun dengan manfaat yang diterima $(B)$ sebesar Rp 100.000.000,- adalah :

$$
\begin{aligned}
& P\left(A_{28: \overline{10}}\right)_{B S}=B\left(A_{28: 10 \mid} B S+A_{28: \frac{1}{10 \mid} B S}\right)=10^{8}(0,224821536+0,39069349) \\
& =61551503,7
\end{aligned}
$$

dan didapatkan premi tunggal dwiguna berjangka $k$-tahun untuk seseorang berusia 1 sampai 55 tahun disajikan pada Tabel 1:

Tabel 1 Harga Premi Tunggal Bersih Dwiguna $k$-Tahun

\begin{tabular}{rrrrr}
\hline Bunga & $\begin{array}{c}\text { Jangka } \\
\text { (tahun) }\end{array}$ & $\begin{array}{c}\text { Asuransi Dwiguna } \\
\text { Berjangka (Rp) }\end{array}$ & $\begin{array}{c}\text { Asuransi Dwiguna } \\
\text { Murni (Rp) }\end{array}$ & Premi (Rp) \\
\hline \multirow{6}{*}{ 6\% } & 10 & $22.482 .153,64,-$ & $39.069 .349,04,-$ & $61.551 .502,7,-$ \\
& 15 & $25.873 .551,53,-$ & $25.616 .941 .53,-$ & $51.490 .493,06,-$ \\
& 20 & $29.125 .042,94,-$ & $16.269 .331,29,-$ & $45.394 .374,22,-$ \\
\hline
\end{tabular}

Berdasarkan Tabel 1 menunjukkan bahwa harga premi yang didapatkan konstan tidak ada perubahan terhadap usia $(t)$ tetapi perubahan hanya pada jangka waktu pembayaran $(k)$, oleh karena itu perubahan tersebut dapat digambarkan dengan grafik yang disajikan pada Gambar 1 sebagai berikut:

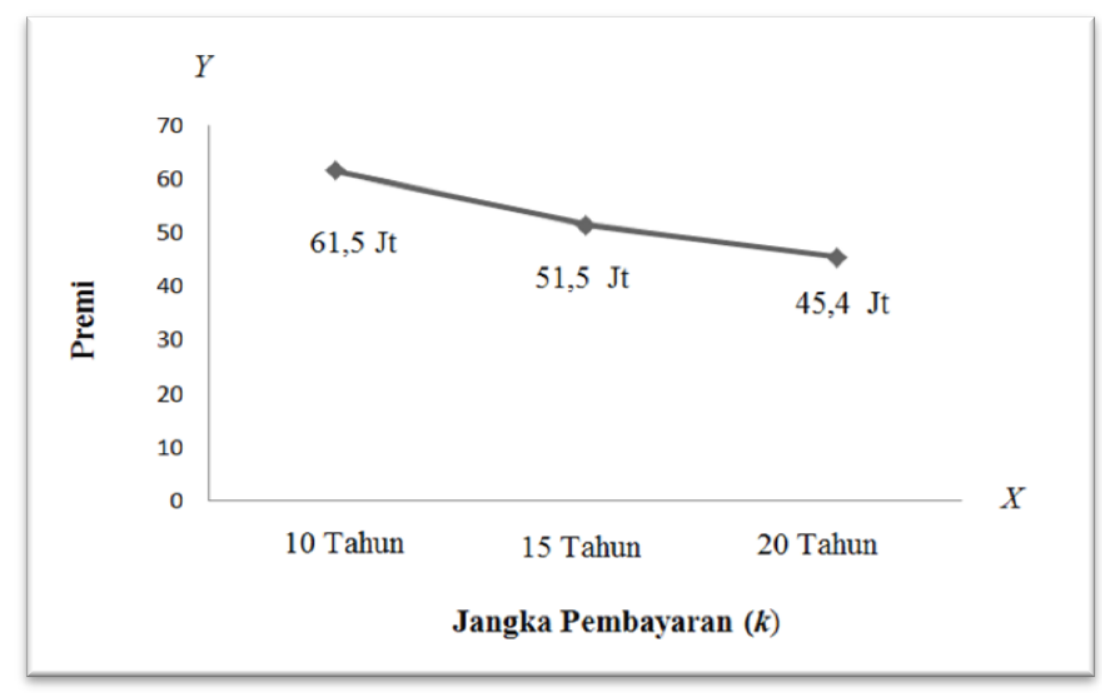

\section{Gambar 1 Premi Dwiguna $k$-Tahun Dengan Model Survival Eksponensial Bayesian SELF}

Berdasarkan Gambar 1 grafik harga premi yang setiap jangka berbeda dan menunjukkan bahwa harga premi akan semakin murah apabila semakin lama jangka waktu pembayaran. Berdasarkan hal tersebut metode ini dapat digunakan untuk kasus asuransi.

\section{PENUTUP}

Berdasarkan tujuan penulisan dan hasil yang diperoleh, dapat ditarik kesimpulan sebagai berikut: 1. Hasil estimasi model survival eksponensial menggunakan Pendekatan Bayesian SELF ialah: 


$$
\hat{S}(t)_{B S}=\left(t_{j} ; \hat{\theta}\right)=e^{\hat{\theta}_{B S} t_{j}}=e^{-\left(\frac{\alpha+n}{\beta+\sum_{j=1}^{n} t_{j}}\right) t_{j}}
$$

2. Premi dwiguna $k$-tahun dengan estimasi model survival eksponensial Bayesian SELF:

$$
P\left(A_{t: k}\right)_{B S}=B\left(\left(\sum_{k=0}^{n-1}\left(\frac{1}{(1+i)}\right)^{k+1} e^{-\left(\frac{\alpha+n}{\beta+\sum_{j=1}^{n} t_{j}}\right)}\left(1-e^{-\left(\frac{\alpha+n}{\beta+\sum_{j=1}^{n} t_{j}}\right)}\right)\right)+\left(\left(\frac{1}{(1+i)}\right)^{k} e^{-\left(\frac{\alpha+n}{\beta+\sum_{j=1}^{n} t_{j}}\right)}\right)\right)
$$

3. Harga premi tunggal bersih dwiguna pada seseorang yang berusia 1 sampai 55 tahun berjangka 10 tahun Rp61.551.502,7,- berjangka 15 tahun Rp51.490.493,06,- dan berjangka 20 tahun Rp45.394.374,22,-. Sehingga dapat dilihat bahwa harga premi akan semakin murah jika jangka pembayaran semakin lama.

\section{SARAN}

Disarankan kepada peneliti selanjutnya jika tertarik mengambil metode Bayesian SELF untuk mempelajari lebih dalam tentang asumsi-asumsi yang harus dipenuhi, sebagai relevansi terhadap kasus yang diambil.

\section{DAFTAR PUSTAKA}

[1]. Futami, T. Seimei Hoken Sugaku, Jokan. Ed ke-3. Japan: The Research Institute Of Life Insurance Welfare; 1993.

[2]. Fitria Syarifah, Helmi and Rizki, S. W. Estimasi Parameter Model Survival Distribusi Eksponensial Data Tersensor Dengan Metode Maksimum Likelihood Dan Bayesian SELF. Bimaster. 2016. Vol. 5.hal. 213-220.

[3]. Lee, E.T. and Wang, J.W. Statistical Methods for Survival Data Analysis. Canada: John Wiley \& Sons Inc; 2003.

[4]. Bolstad, W. Introduction to Bayesian Statistics. Ed ke-2. Amerika: John Wiley \& Sons, Inc; 2007.

[5]. Bain, L. J. and Engelhardt, M. Introduction to Probability and Mathematical Statistics. Ed ke-2. California: Duxbury of Wathfor, Inc; 1992.

[6]. Guure, C.B., and Ibrahim, N. A. Bayesian Analysis Survival Function and Failure Rate of Weibull Distribution with Censored Data. Journal Mathematical Problems in Engineering. 2012; Vol 1: Article ID 329489

[7]. Bowers, N. L. et al. Actuarial Mathematics. Second Edition. The Sociaty of Actuaries, USA; 1997.

[8]. Siegel, S. Nonparametric Statistics : For The Behavioral Sciences. MeGraw-Hill Book Company Inc, New York; 1986.

[9]. BI 7-day (Reverse) Repo Rate From: Https://www.bi.go.id/id/moneter/bi-7day RR/data/Contents/Default.aspx.

\section{LISA NOVIANI}

SETYO WIRA RIZKI

NAOMI NESSYANA DEBATARAJA : Fakultas MIPA Universitas Tanjungpura, Pontianak,

naominessyana@math.untan.ac.id

: Fakultas MIPA Universitas Tanjungpura, Pontianak, lisanovi@student.untan.ac.id.

: Fakultas MIPA Universitas Tanjungpura, Pontianak, setyo.wirarizki@math.untan.ac.id 